\title{
Erythropoiesis-stimulating Agent Use among Patients with Lupus Nephritis Approaching End- stage Renal Disease
}

\section{Citation}

Gómez-Puerta, José A, Sushrut S Waikar, Daniel H Solomon, Jun Liu, Graciela S Alarcón, Wolfgang C Winkelmayer, and Karen H Costenbader. 2013. "Erythropoiesis-stimulating Agent Use among Patients with Lupus Nephritis Approaching End-stage Renal Disease." Journal of clinical \& cellular immunology 4 (6): 179. doi:10.4172/2155-9899.1000179. http:// dx.doi.org/10.4172/2155-9899.1000179.

\section{Published Version}

doi:10.4172/2155-9899.1000179

\section{Permanent link}

http://nrs.harvard.edu/urn-3:HUL.InstRepos:12064491

\section{Terms of Use}

This article was downloaded from Harvard University's DASH repository, and is made available under the terms and conditions applicable to Other Posted Material, as set forth at http:// nrs.harvard.edu/urn-3:HUL.InstRepos:dash.current.terms-of-use\#LAA

\section{Share Your Story}

The Harvard community has made this article openly available.

Please share how this access benefits you. Submit a story.

Accessibility 


\title{
Erythropoiesis-stimulating Agent Use among Patients with Lupus Nephritis Approaching End-stage Renal Disease
}

\author{
José A Gómez-Puerta ${ }^{1,}$, , Sushrut S Waikar ${ }^{2}$, Daniel H Solomon ${ }^{1,3}$, Jun Liu ${ }^{3}$, Graciela S \\ Alarcón ${ }^{4}$, Wolfgang C Winkelmayer ${ }^{5}$, and Karen H Costenbader ${ }^{1}$ \\ ${ }^{1}$ Division of Rheumatology, Immunology, and Allergy, Department of Medicine, Brigham and \\ Women's Hospital, Harvard Medical School, Boston, MA, USA \\ 2Division of Nephrology, Department of Medicine, Brigham and Women's Hospital, Harvard \\ Medical School, Boston, MA, USA \\ ${ }^{3}$ Division of Pharmacoepidemiology, Department of Medicine, Brigham and Women's Hospital, \\ Harvard Medical School, Boston, MA, USA \\ ${ }^{4}$ Division of Rheumatology and Clinical Immunology, University of Alabama at Birmingham, \\ Birmingham, AL, USA \\ ${ }^{5}$ Division of Nephrology, Stanford University School of Medicine, Palo Alto, CA, USA
}

\begin{abstract}
Objectives-Little is known about erythropoiesis-stimulating agents (ESAs) utilization among lupus nephritis (LN) patients with incipient ESRD. We aimed to identify sociodemographic and clinical factors associated with ESA use among incident LN ESRD patients.
\end{abstract}

\begin{abstract}
Methods-Among all individuals age $\geq 18$ with incident ESRD from 1995-2008 in the U.S. Renal Data System (USRDS), we identified those with systemic lupus erythematosus (ICD-9 code 710.0) as the cause of ESRD. ESA use at ESRD onset was ascertained from the Medical Evidence Report. Year of onset, age, sex, race/ethnicity, medical insurance, employment status, residential region, clinical factors and comorbidities were considered potentially associated with ESA use in multivariable-adjusted logistic regression analyses.
\end{abstract}

\begin{abstract}
Results-We identified 12,533 individuals with incident LN ESRD (1\% of entire population). Of those, 4,288 (34\%) received an ESA preceding ESRD. In multivariable-adjusted models, ESA users had higher serum albumin and hemoglobin concentrations, were more likely to be women, and to live in the Northeast. Conversely, Medicaid beneficiaries, the uninsured, unemployed, African Americans, Hispanics, and those with IV drug use, congestive heart failure and obesity had lower ESA use.
\end{abstract}

Conclusion-Among all U.S. patients and those with LN who developed ESRD, approximately one third received ESAs. Patient sex, race, age, medical insurance, residential region and clinical factors were significantly associated with ESA therapy. While there are no guidelines for ESA use

Copyright: () 2013 Gómez-Puerta JA, et al.

This is an open-access article distributed under the terms of the Creative Commons Attribution License, which permits unrestricted use, distribution, and reproduction in any medium, provided the original author and source are credited.

"Corresponding author: Section of Clinical Sciences, Division of Rheumatology, Immunology and Allergy, PBB-B3, Brigham and Women’s Hospital. 221 Longwood Ave, MA 02115, USA, Tel: 617-264-5908; Fax: 617-264-3019; jgomezpuerta@ partners.org.

Disclaimer Data for these analyses were provided by United States Renal Data System (USRDS), but the analysis and conclusions are those of the authors and do not represent the USRDS or National Institute of Diabetes and Digestive and Kidney Diseases (NIDDK). 
in LN patients approaching ESRD, there has been wide sociodemographic variation, raising questions about ESA prescription practices.

\section{Keywords}

Lupus nephritis; End-stage renal disease; Erythropoiesis-stimulating agents; Anemia; Disparity; Race; Ethnicity; Access to care; Sociodemographic

\section{Introduction}

Systemic lupus erythematosus (SLE) is an autoimmune disease of unknown etiology which can cause multiorgan system damage and which disproportionately affects women and nonCaucasian minorities. Up to $60 \%$ of SLE patients develop renal disease, lupus nephritis (LN), and of these, approximately one fifth progress to end-stage renal disease (ESRD) within 10 years [1,2]. As LN progresses, anemia is a common clinical problem. The use of recombinant human erythropoiesis-stimulating agents (ESAs) for patients with chronic kidney disease-associated anemia, first approved in 1989, has resulted in substantial clinical benefits, including correction of anemia and improvement of symptoms such as fatigue, decreased cognition and mental acuity, as well as improved quality of life, reduction of the need for ongoing transfusions and iron supplements $[3,4]$.

Among patients with LN in the U.S., African Americans, Hispanics, and patients in lower socioeconomic classes have poorer prognoses [5]. These sociodemographic groups have also been found to have more severe laboratory abnormalities (higher serum creatinine and lower hematocrit levels) at the start of renal replacement therapy for ESRD of all causes [6]. Differential access to healthcare, such as primary preventive care, specialized physician care, indicated medications and procedures, may contribute to observed sociodemographic disparities in the development of LN ESRD and death. Among patients with LN-associated ESRD, we have found that being young, White, employed, and living in an area of higher socioeconomic class, were all strongly associated with increased chances of receiving a renal transplant or peritoneal dialysis, as opposed to hemodialysis, as the initial renal replacement therapy [5].

Patterns of ESA use for anemia among patients with $\mathrm{LN}$-associated chronic kidney disease, however, have never been examined. It is not known what proportion of LN patients receive ESAs, nor which clinical and sociodemographic factors influence prescribing patterns. In the present study, we investigated sociodemographic and clinical factors associated with use of ESAs prior to renal replacement therapy for LN-associated ESRD in the U.S from 1995-2008.

\section{Methods}

\section{Study population}

The US Renal Data System (USRDS) is the U.S. national registry of patients with ESRD [6]. We conducted a cross-sectional study that included all individuals age $\geq 18$ with incident ESRD secondary to systemic lupus erythematosus (ICD-9 code 710.0) from 1995 to 2008 in the USRDS. The Partners' Healthcare Institutional Review Board reviewed this study protocol and granted it a waiver as human subjects' exempt research. A data use agreement with USRDS was obtained for this study. 


\section{Data collection}

Use of ESAs at the time of renal replacement therapy initiation (dialysis or kidney transplantation) was ascertained from the Medical Evidence Report (CMS form 2728), completed by attending nephrologists and required by the U.S. government. The Medical Evidence Report contains patient demographic information, including age at the time of initiation of renal replacement therapy, sex, race (White, African American, Asian, or American Indian), Hispanic ethnicity, and state and zip code of residence. It also records the individual's body mass index (BMI; categorized as underweight $<18$, normal $>18$ to 25 , and obese $>25 \mathrm{~kg} / \mathrm{m}^{2}$ ), and diagnosed comorbidities, including hypertension, diabetes mellitus, coronary artery disease (CAD), peripheral vascular disease (PVD), chronic obstructive pulmonary disease, cancer, cerebrovascular accidents (CVA), congestive heart failure (CHF), previous smoking history, and intravenous drug abuse. Certain laboratory measurements, including serum levels of estimated glomerular filtration rate (eGFR), albumin and hemoglobin, are reported. The type of medical insurance prior to the onset of ESRD is also recorded (private, Medicaid, Medicare, other, or none).

\section{Statistical analyses}

We examined trends in the use of ESAs among those with incident LN-associated ESRD over time, for all and in different sociodemographic groups, using Cochane-Armitage tests for trends. We employed univariable analyses (Chi squared tests for categorical variables and t-tests for continuous variables) to identify factors associated with receipt of an ESA at ESRD onset among LN-associated ESRD patients. Multiple imputation analyses were used for missing baseline data [albumin, body mass index and eGFR]. We then developed multivariable-adjusted logistic regression models including these variables to identify factors independently associated with ESA receipt. Potential factors examined included calendar year of ESRD onset, age, sex, race, Hispanic ethnicity, U.S. region of residence (categorized by U.S. state as Northeast, Midwest, South, or West), comorbidities and type of medical insurance and clinical laboratory values (hemoglobin, albumin, eGFR). All $p$ values were calculated with two-sided significance level of 0.05 . Data analyses were performed using SAS 9.2 (SAS Institute, Inc, Cary, North Carolina).

\section{Results}

From 1995 to 2008, there were 1,138,133 patients over age 18 with new onset ESRD of any cause in the U.S. In this entire population, 29\% of new ESRD patients received ESA therapy. Within this group, we identified 12,533 individuals with incident lupus nephritisassociated ESRD (1.0\% of all patients), of whom 4,288 (34\%) were currently receiving ESA therapy. Eighty-two percent of LN-associated ESRD patients were female, mean age was $40.7 \pm 15$ years, and $49 \%$ were African American. There was a steady increase in the proportion of patients with LN ESRD that received ESA therapy: 30\% of patients in $1995-1998,35 \%$ in $1999-2001$, and $37 \%$ in $2002-2005$ and a slight decline thereafter to $35 \%$ in 2006-2008. This increase was observed in all racial and ethnic groups. Figure 1 demonstrates ESA use among patients with LN-associated ESRD, according to sex, race, ethnicity and region of residence.

Baseline characteristics of patients with new onset LN-associated ESRD are shown in Table 1 according to ESA use. Compared to those not receiving ESAs, higher proportions of LN ESRD patients receiving ESAs were white or Asian, were of normal weight (vs. overweight or obese), were in categories of high hemoglobin and albumin levels at ESRD onset, were employed, had private health insurance, and lived in the Northeast. 
In univariable and multivariable-adjusted models, several sociodemographic factors were strongly associated with the odds of receiving ESAs at the onset of LN-associated ESRD (Table 2). Men (compared to women), African Americans (compared to Whites), Hispanics (compared to non-Hispanics), those with Medicaid or no medical insurance (compared to private insurance), those living in any region of the US compared to Northeast, and those who were unemployed (compared to employed) all had significantly reduced odds of receiving ESA treatment at the onset of ESRD. Clinical factors were also strongly associated with receipt of ESAs. Patients who were obese (compared to those of normal BMI) and those who had low serum albumin $(2.5 \mathrm{mg} / \mathrm{dL}$ or lower compared to those with albumin $>2.5$ $\mathrm{mg} / \mathrm{dl}$ ) had significantly lower odds of receiving ESAs. Patients who had hemoglobin levels $<8.5 \mathrm{mg} / \mathrm{dl}$ (compared to those with hemoglobin levels between 8.6 to $10 \mathrm{mg} / \mathrm{dl}$ ) had lower odds of receiving ESAs, as did patients with higher eGFR at ESRD onset ( $\geq 10.0 \mathrm{ml} / \mathrm{min}$ vs. $<10 \mathrm{ml} / \mathrm{min}$ ). Some comorbidities were associated with reduced odds of receiving ESAs, including congestive heart failure and intravenous drug abuse. However, others, such as $\mathrm{CAD}$, hypertension and peripheral vascular disease were associated with increased odds of receiving ESA therapy.

\section{Discussion}

The present study included more than 12,000 U.S. patients with incident $\mathrm{LN}$-associated ESRD, approximately $1 \%$ of the incident all-cause ESRD population, in the U.S from 1995-2008 to examine use of ESAs at ESRD onset in this population in particular. We examined a range of clinical and sociodemographic factors to understand variation on their use for this population. Thirty-four percent of LN patients received ESAs prior to initiating renal replacement therapy, a slightly higher proportion than that of the entire USRDS population. There was an increase in the use of ESAs from 1995 to 2005 and a slight drop thereafter, as in the general US ESRD population [7]. Recommendations for ESA use among patients with advanced chronic kidney disease are still evolving, taking into account data from recent trials [8]. Randomized controlled trials in the past 6 years have demonstrated increased risks of adverse cardiovascular events in individuals with high hemoglobin levels (>12 or $13 \mathrm{~g} / \mathrm{dl}$ ) receiving ESAs [7,9-11]. The reduction in ESA use observed after 2005 may be explained by the publication and dissemination of these results.

In models simultaneously adjusting for multiple sociodemographic and clinical factors among patients with new onset LN ESRD, we have found that women were more likely to receive ESAs prior to renal replacement therapy initiation than men. African Americans were less likely than whites and Hispanics were less likely than non-Hispanic patients to receive ESAs. Our results are congruent with two past studies that examined sociodemographic factors associated with ESA use in the new onset ESRD population in the U.S. in the 1990s; African Americans were less likely than Whites and Hispanics were less likely than non-Hispanics to receive ESAs [5,12]. This suggests that the racial and ethnic disparities we have observed are pervasive and persistent.

We have found that patients with clinical or laboratory values indicating better health, such as normal (vs. obese) BMI, and higher serum albumin and hemoglobin levels, also had higher ESA use. It is not clear that this variation was clinically indicated. We have previously demonstrated similar sociodemographic variation in the choice of initial treatment modality for LN ESRD (peritoneal dialysis, hemodialysis and pre-emptive renal transplant), according to clinical parameters which indicate overall superior health and quality of medical care [5]. Just as pre-emptive renal transplant and peritoneal dialysis appear to be limited to an advantaged group of LN ESRD patients, ESA therapy appears to be prescribed unequally across clinical and sociodemographic strata of the population. 
Medical insurance and region of residence were also important factors in determining the receipt of ESAs among patients with LN approaching ESRD. Individuals with Medicaid and no medical insurance, those who were unemployed, as well as those who lived in the South, West and Midwest regions (compared to the Northeast), all were less like to have received ESA therapy at the time of renal replacement therapy onset. We have observed similar patterns for variation in renal replacement therapy modalities for LN ESRD patients [5].

Physicians caring for LN patients may not be aware of the striking sociodemographic variation in use of ESAs among patients with LN-associated ESRD. Despite one third of patients with LN-associated ESRD receiving ESA therapy, there are currently no guidelines for ESA use among LN patients. The 2012 Kidney Disease Improving Global Outcomes (KDIGO) guidelines have recently recommended ESA therapy for all dialysis patients when hemoglobin levels are between $9-10 \mathrm{~g} / \mathrm{dl}$ and their use to maintain hemoglobin levels $>9.0 \mathrm{~g} /$ dl [7]. Recently published guidelines for the treatment of $\mathrm{LN}$, however, have not addressed ESA use $[13,14]$. LN patients have potential complications and comorbidities to be weighed in the decision to use ESAs, including hypertension, increased risk of cardiovascular disease, driven in part by systemic inflammation, and increased risk for thromboembolic events due to inflammation and other pro-coagulant factors such as antiphospholipid antibodies [15]. The decision to use ESA therapy for LN-associated anemia, as well as the choice of initial modality for ESRD treatment, is likely influenced by healthcare provider preference and by patient knowledge and preference. Moreover, ESAs are expensive, which may influence the treating physician's decision [16]. In the current multivariable models, we found that patients with CAD, hypertension and peripheral vascular disease all had increased odds of receiving ESA therapy. It is likely that providers were motivated to treat anemia with ESAs in those with underlying atherosclerotic disease. However, in the absence of clear guidelines or recommendations, striking sociodemographic variation in their use exists.

This is the first and only large observational study of ESA therapy among LN ESRD patients, examining trends and factors associated with their use. Its strengths include its large and inclusive population, and detailed clinical and sociodemographic data. The USRDS includes clinical parameters specifically related to ESRD, but no data concerning underlying SLE disease activity or specific previous immunosuppressive therapy unfortunately. Additionally, no data concerning dose and duration of ESA use prior to the onset of ESRD were available. A recent report compared the concordance between the records from the USRDS and the records from the Department of Veteran Affairs (VA) concerning ESA use at ESRD onset, and demonstrated under-recording of ESA use in 4\% of cases, reflecting a limitation to data accuracy [17]. The likely effect of such misclassification is a bias towards the null; hence, our estimates of association can be considered to be conservative. Our findings also may not be generalizable to other countries. The Dialysis Outcomes and Practice Patterns Study (DOPPS) revealed variation in ESA use at the start of dialysis with 50\% of patients receiving them in Australia and New Zealand and 30 to $65 \%$ in European countries [18].

Many concerns about safety of ESA use in patients with ESRD and LN-associated ESRD remain unresolved. We have found that approximately one third of patients with ESRD related to $\mathrm{LN}$ are receiving ESA treatment as ESRD onset. Those patients with better health care access and superior clinical parameters had higher likelihoods of receiving ESAs. Until we have a better understanding of the risks and benefits associated with their use in this population, the sociodemographic disparities in access to these medications will likely persist. Understanding whether and how ESAs are indicated and developing guidelines for their use in patients with LN-associated ESRD is an important research goal. 


\section{Acknowledgments}

Funding Statement This work was supported by the National Institute of Arthritis and Musculoskeletal and Skin Diseases of the National Institutes of Health under Award Number R01 AR057327. The content is solely the responsibility of the authors and does not necessarily represent the official views of the National Institutes of Health. JA Gómez-Puerta was supported Spanish Society of Rheumatology, Catalan Society of Rheumatology by Fundación Alfonso Martin Escudero.

\section{References}

1. Wallace DJ, Podell TE, Weiner JM, Cox MB, Klinenberg JR, et al. Lupus nephritis. Experience with 230 patients in a private practice from 1950 to 1980. Am J Med. 1982; 72:209-220. [PubMed: 7058833]

2. Dooley MA, Hogan S, Jennette C, Falk R. Cyclophosphamide therapy for lupus nephritis: poor renal survival in black Americans. Glomerular Disease Collaborative Network. Kidney Int. 1997; 51:1188-1195. [PubMed: 9083285]

3. Levin NW, Lazarus JM, Nissenson AR. National Cooperative rHu Erythropoietin Study in patients with chronic renal failure--an interim report. The National Cooperative rHu Erythropoietin Study Group. Am J Kidney Dis. 1993; 22:3-12. [PubMed: 8352269]

4. Pickett JL, Theberge DC, Brown WS, Schweitzer SU, Nissenson AR. Normalizing hematocrit in dialysis patients improves brain function. Am J Kidney Dis. 1999; 33:1122-1130. [PubMed: 10352201]

5. Devlin A, Waikar SS, Solomon DH, Lu B, Shaykevich T, et al. Variation in initial kidney replacement therapy for end-stage renal disease due to lupus nephritis in the United States. Arthritis Care Res (Hoboken). 2011; 63:1642-1653. [PubMed: 22058067]

6. United States Renal Data System. Researcher's guide to the USRDS database. In: ADR., editor. National Institute of Diabetes and Digestive and Kidney Diseases DoK. Urologic, and Hematologic Diseases, NIH; Bethesda, MD, USA: 2009.

7. Drüeke TB, Locatelli F, Clyne N, Eckardt KU, Macdougall IC, et al. Normalization of hemoglobin level in patients with chronic kidney disease and anemia. N Engl J Med. 2006; 355:2071-2084. [PubMed: 17108342]

8. Kidney Disease: Improving Global Outcomes (KDIGO); Anemia Work Group. KDIGO Clinical Practice Guideline for Anemia in Chronic Kidney Disease. Kidney Int Suppl. 2012; 2:279-335.

9. Singh AK, Szczech L, Tang KL, Barnhart H, Sapp S, et al. Correction of anemia with epoetin alfa in chronic kidney disease. N Engl J Med. 2006; 355:2085-2098. [PubMed: 17108343]

10. Pfeffer MA, Burdmann EA, Chen CY, Cooper ME, de Zeeuw D, et al. A trial of darbepoetin alfa in type 2 diabetes and chronic kidney disease. N Engl J Med. 2009; 361:2019-2032. [PubMed: 19880844]

11. Winkelmayer WC. What caused excess strokes in patients randomized to darbepoetin in the trial to reduce cardiovascular events with Aranesp therapy (TREAT)?: no smoking gun. Circulation. 2011; 124:2805-2808. [PubMed: 22184042]

12. Weisbord SD, Fried LF, Mor MK, Resnick AL, Kimmel PL, et al. Associations of race and ethnicity with anemia management among patients initiating renal replacement therapy. $\mathrm{J}$ Natl Med Assoc. 2007; 99:1218-1226. [PubMed: 18020096]

13. Hahn BH, McMahon MA, Wilkinson A, Wallace WD, Daikh DI, et al. American College of Rheumatology guidelines for screening, treatment, and management of lupus nephritis. Arthritis Care Res (Hoboken). 2012; 64:797-808. [PubMed: 22556106]

14. Bertsias GK, Tektonidou M, Amoura Z, Aringer M, Bajema I, et al. Joint European League Against Rheumatism and European Renal Association-European Dialysis and Transplant Association (EULAR/ERA-EDTA) recommendations for the management of adult and paediatric lupus nephritis. Ann Rheum Dis. 2012; 71:1771-1782. [PubMed: 22851469]

15. Mok CC, Tang SS, To CH, Petri M. Incidence and risk factors of thromboembolism in systemic lupus erythematosus: a comparison of three ethnic groups. Arthritis Rheum. 2005; 52:2774-2782. [PubMed: 16142761] 
16. Clement FM, Klarenbach S, Tonelli M, Wiebe N, Hemmelgarn B, et al. An economic evaluation of erythropoiesis-stimulating agents in CKD. Am J Kidney Dis. 2010; 56:1050-1061. [PubMed: 20932621]

17. Fischer MJ, Stroupe KT, Hynes DM, Blemur P, Sohn MW, et al. Validation of erythropoietin use data on Medicare's End-Stage Renal Disease Medical Evidence Report. J Rehabil Res Dev. 2010; 47:751-762. [PubMed: 21110249]

18. Pisoni RL, Bragg-Gresham JL, Young EW, Akizawa T, Asano Y, et al. Anemia management and outcomes from 12 countries in the Dialysis Outcomes and Practice Patterns Study (DOPPS). Am J Kidney Dis. 2004; 44:94-111. [PubMed: 15211443] 
A

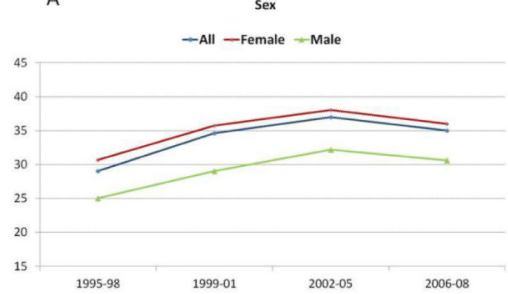

Ethnicity

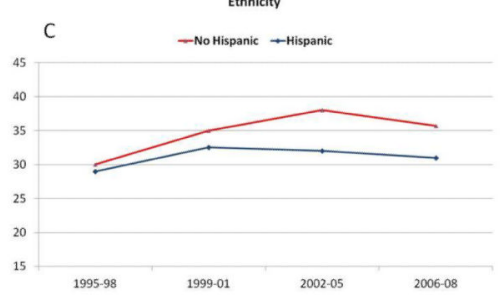

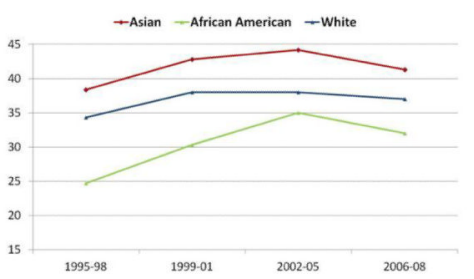

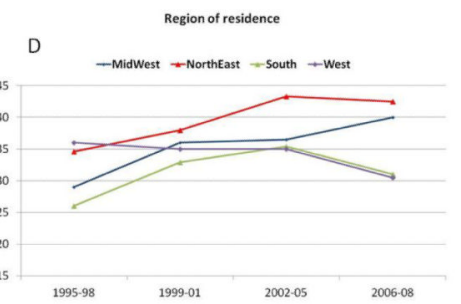

Figure 1.

Percentage of patients receiving ESA overt time in Patients with LN-associated ESRD. Analysis according to: (A) Sex, (B) Race (Asian, African American and White), (C) Ethnicity and (D) Region of residence (Midwest, NorthEast, South and West). 


\section{Table 1}

Baseline Characteristics of U.S. Patients with Lupus Nephritis associated ESRD, 1995-2008 (N=12,533).

\begin{tabular}{|c|c|c|c|}
\hline & $\begin{array}{l}\text { ESA Use } \\
\mathbf{N}=\mathbf{4 , 2 8 8}\end{array}$ & $\begin{array}{l}\text { No ESA Use } \\
\mathbf{N = 8 , 2 4 5}\end{array}$ & $p$ value \\
\hline Female, $(\%)$ & $3,606(84)$ & $6,622(80)$ & $<0.001$ \\
\hline Age (years), (SD) & $42.2(14.8)$ & $39.9(14.9)$ & 0.85 \\
\hline \multicolumn{4}{|l|}{ Race, $(\%)$} \\
\hline African American & $1,912(44)$ & $4,269(52)$ & $<0.001$ \\
\hline White & $2,047(48)$ & $3,500(42)$ & \\
\hline Asian & $286(7)$ & $397(5)$ & \\
\hline Native American & $43(1)$ & $79(1)$ & \\
\hline \multicolumn{4}{|l|}{ Ethnicity, (\%) } \\
\hline Hispanic & $637(15)$ & $1,394(17)$ & 0.003 \\
\hline \multicolumn{4}{|l|}{ BMI $\left(\mathrm{kg} / \mathrm{m}^{2}\right),(\%)$} \\
\hline Underweight BMI<18 & $360(8)$ & $594(7)$ & 0.001 \\
\hline $18-25$ & $1,890(44)$ & $3,470(42)$ & \\
\hline Overweight/Obesity BMI>25 & $2,038(48)$ & $4,181(51)$ & \\
\hline \multicolumn{4}{|l|}{ Serum albumin $(\mathrm{mg} / \mathrm{dl}),(\%)$} \\
\hline 2.5 & $988(23)$ & $2,864(35)$ & $<0.001$ \\
\hline $2.6-3.2$ & $1,389(32)$ & $2,745(33)$ & \\
\hline$\geq 3.3$ & $1,911(45)$ & $2,636(32)$ & \\
\hline \multicolumn{4}{|l|}{ Hemoglobin (mg/dl), $(\%)$} \\
\hline$\$ 8.5$ & $1,132(26)$ & $2,926(36)$ & $<0.001$ \\
\hline $8.6-10$ & $1,445(34)$ & $2,734(33)$ & \\
\hline$\geq 10$ & $1,711(40)$ & $2,585(31)$ & \\
\hline \multicolumn{4}{|l|}{ eGFR (ml/min), $(\%)$} \\
\hline 5.0 & $926(22)$ & $1,898(23)$ & 0.003 \\
\hline $5.0-10.0$ & $2,400(56)$ & $4,352(53)$ & \\
\hline$\geq 10.0$ & $962(22)$ & $1,995(24)$ & \\
\hline \multicolumn{4}{|l|}{ Medical insurance type, $(\%)$} \\
\hline Private & $1,438(34)$ & $2,266(27)$ & $<0.001$ \\
\hline Medicaid & $1,244(29)$ & $2,770(34)$ & \\
\hline No insurance & $247(6)$ & $1,068(13)$ & \\
\hline Medicare & $840(20)$ & $1217(15)$ & \\
\hline \multicolumn{4}{|l|}{ Employment at ESRD onset, (\%) } \\
\hline Employed & $984(23)$ & $1,477(18)$ & $<0.001$ \\
\hline Unemployed & $3,304(77)$ & $6,768(82)$ & \\
\hline \multicolumn{4}{|l|}{ U.S. region of residence, $(\%)$} \\
\hline Northeast & $830(20)$ & $1,249(15)$ & $<0.001$ \\
\hline West & 817 (19) & $1,573(19)$ & \\
\hline
\end{tabular}




\begin{tabular}{|l|c|c|c|}
\hline & $\begin{array}{c}\text { ESA Use } \\
\mathbf{N = 4 , 2 8 8}\end{array}$ & $\begin{array}{c}\text { No ESA Use } \\
\mathbf{N = 8 , 2 4 5}\end{array}$ & p value \\
\hline South & $1,723(41)$ & $3,721(40)$ & \\
\hline Midwest & $857(20)$ & $1,572(19)$ & \\
\hline Comorbidities, (\%) & & & \\
\hline Hypertension & $3,469(81)$ & $6,173(74)$ & $<0.001$ \\
\hline Coronary artery disease & $372(9)$ & $473(6)$ & $<0.001$ \\
\hline Peripheral vascular disease & $176(4)$ & $241(3)$ & $<0.001$ \\
\hline Diabetes mellitus & $399(9)$ & $724(9)$ & 0.32 \\
\hline Congestive heart failure & $631(15)$ & $1,327(16)$ & 0.04 \\
\hline Chronic obstructive pulmonary disease & $106(2)$ & $189(2)$ & 0.52 \\
\hline Cerebrovascular accident & $251(39)$ & $398(5)$ & 0.01 \\
\hline Current smoking & $153(4)$ & $342(4)$ & 0.11 \\
\hline IV Drug abuse & $17(0.4)$ & $78(1)$ & $<0.001$ \\
\hline Cancer & $81(2)$ & $108(1)$ & 0.01 \\
\hline
\end{tabular}

*

t-test for age and Chi-squared tests for categorical variables comparing LN ESRD patients receiving vs. not receiving ESA. 
Table 2

Sociodemographic and Clinical Factors Significantly Associated with ESA use at Onset of ESRD among 12,533 U.S. Patients with LN from 1995-2008.

\begin{tabular}{|c|c|c|c|c|}
\hline & $\begin{array}{l}\text { Univariable } \\
\quad \text { OR }\end{array}$ & $95 \%$ CI & $\begin{array}{l}\text { Multivariable- Adjusted* } \\
\text { OR }\end{array}$ & $95 \% \mathrm{CI}$ \\
\hline \multicolumn{5}{|l|}{ Sex } \\
\hline Female & 1.0 (ref.) & - & 1.0 (ref.) & - \\
\hline Male & 0.76 & $0.69-0.84$ & 0.73 & $0.66-0.81$ \\
\hline \multicolumn{5}{|l|}{ Age in years } \\
\hline $18-29$ & 0.80 & $0.72-0.89$ & 0.92 & $0.82-1.03$ \\
\hline $30-39$ & 1.0 (ref.) & - & $1.0(\mathrm{ref})$ & - \\
\hline $40-49$ & 1.10 & $0.99-1.23$ & 1.00 & $0.89-1.12$ \\
\hline$>50$ & 1.23 & $1.11-1.36$ & 0.99 & $0.89-1.11$ \\
\hline \multicolumn{5}{|l|}{ Year of ESRD onset } \\
\hline 1995-1998 & 0.79 & $0.70-0.88$ & 0.77 & $0.69-0.87$ \\
\hline 1999-2001 & 0.98 & $0.88-1.09$ & 0.96 & $0.86-1.08$ \\
\hline $2002-2004$ & 1.09 & $0.99-1.20$ & 1.05 & $0.94-1.16$ \\
\hline 2005-2008 & 1.0 (ref.) & - & $1.0(\mathrm{ref})$ & - \\
\hline \multicolumn{5}{|l|}{ Medical Insurance } \\
\hline Private & 1.0 (ref.) & - & 1.0 (ref.) & - \\
\hline Medicaid & 0.73 & $0.67-0.81$ & 0.84 & $0.75-0.94$ \\
\hline No insurance & 0.38 & $0.33-0.44$ & 0.45 & $0.38-0.53$ \\
\hline Medicare & 1.03 & $0.92-1.16$ & 1.07 & $0.95-1.22$ \\
\hline \multicolumn{5}{|l|}{ Race } \\
\hline White & 1.0 (ref.) & - & $1.0(\mathrm{ref})$ & - \\
\hline African American & 0.79 & $0.73-0.85$ & 0.74 & $0.68-0.82$ \\
\hline Asian & 1.31 & $1.11-1.54$ & 1.18 & $0.99-1.41$ \\
\hline Native American & 0.96 & $0.66-1.40$ & 0.89 & $0.60-1.31$ \\
\hline \multicolumn{5}{|l|}{ Ethnicity } \\
\hline Hispanic & 0.91 & $0.82-1.00$ & 0.87 & $0.77-0.98$ \\
\hline \multicolumn{5}{|l|}{ Region of Residence } \\
\hline Northeast & 1.0 (ref.) & - & $1.0(\mathrm{ref})$ & - \\
\hline West & 0.80 & $0.71-0.91$ & 0.72 & $0.64-0.83$ \\
\hline South & 0.71 & $0.64-0.79$ & 0.78 & $0.70-0.88$ \\
\hline Midwest & 0.82 & $0.73-0.93$ & 0.82 & $0.72-0.93$ \\
\hline \multicolumn{5}{|c|}{ Employment at ESRD onset } \\
\hline Employed & 1.0 (ref.) & - & 1.0 (ref) & - \\
\hline Unemployed & 0.73 & $0.66-0.80$ & 0.85 & $0.76-0.94$ \\
\hline \multicolumn{5}{|l|}{ BMI $\left(\mathrm{kg} / \mathrm{m}^{2}\right)$} \\
\hline Underweight $\mathrm{BMI}<18$ & 1.10 & $0.95-1.27$ & 1.16 & $1.00-1.35$ \\
\hline
\end{tabular}




\begin{tabular}{|c|c|c|c|c|}
\hline & $\begin{array}{l}\text { Univariable } \\
\text { OR }\end{array}$ & $95 \%$ CI & $\begin{array}{c}\text { Multivariable- Adjusted } \\
\text { OR }\end{array}$ & $95 \% \mathrm{CI}$ \\
\hline $18-25$ & 1.0 (ref.) & - & 1.0 (ref) & - \\
\hline Overweight/Obesity BMI>25 & 0.88 & $0.82-0.95$ & 0.87 & $0.80-0.94$ \\
\hline \multicolumn{5}{|l|}{ Serum albumin (mg/dl) } \\
\hline $\mathcal{2} .5$ & 0.70 & $0.64-0.77$ & 0.73 & $0.66-0.81$ \\
\hline $2.6-3.2$ & 1.0 (ref) & - & 1.0 (ref) & - \\
\hline$>3.3$ & 1.43 & $1.31-1.56$ & 1.35 & $1.23-1.48$ \\
\hline \multicolumn{5}{|l|}{ Hemoglobin (mg/dl) } \\
\hline$\$ 8.5$ & 0.75 & $0.68-0.83$ & 0.80 & $0.72-0.88$ \\
\hline $8.6-10$ & 1.0 (ref) & - & 1.0 (ref) & - \\
\hline$>10$ & 1.22 & $1.12-1.34$ & 1.13 & $1.03-1.24$ \\
\hline \multicolumn{5}{|l|}{ eGFR (ml/min) } \\
\hline$\unlhd) .0$ & 0.88 & $0.80-0.97$ & 1.00 & $0.90-1.10$ \\
\hline $5.0-10.0$ & 1.0 (ref) & - & 1.0 (ref) & - \\
\hline$>10.0$ & 0.89 & $0.81-0.97$ & 0.86 & $0.78-0.95$ \\
\hline \multicolumn{5}{|l|}{ Comorbidities } \\
\hline Hypertension & 1.40 & $1.28-1.53$ & 1.40 & $1.27-1.54$ \\
\hline Coronary artery disease & 1.40 & $1.21-1.62$ & 1.36 & $1.17-1.60$ \\
\hline Peripheral vascular disease & 1.31 & $1.07-1.59$ & 1.31 & $1.06-1.61$ \\
\hline Diabetes mellitus & 0.98 & $0.86-1.12$ & 1.08 & $0.94-1.23$ \\
\hline Congestive heart failure & 0.85 & $0.76-0.94$ & 0.88 & $0.79-0.99$ \\
\hline Chronic pulmonary obstructive disease & 0.94 & $0.74-1.20$ & 0.90 & $0.70-1.17$ \\
\hline Cerebrovascular accident & 1.16 & $0.99-1.37$ & 1.10 & $0.93-1.31$ \\
\hline Current smoking & 0.83 & $0.68-1.00$ & 0.83 & $0.67-1.02$ \\
\hline IV Drug abuse & 0.42 & $0.25-0.71$ & 0.56 & $0.32-0.97$ \\
\hline Cancer & 1.28 & $0.96-1.72$ & 1.22 & $0.90-1.66$ \\
\hline
\end{tabular}

eGFR: Estimated Glomerular Filtration Rate; ESA: Erythropoiesis-Stimulating Agent; LN: Lupus Nephritis; ESRD: End-Stage Renal Disease; OR: Odds Ratio.

* Multivariable analysis adjusted for all variables in the table. 